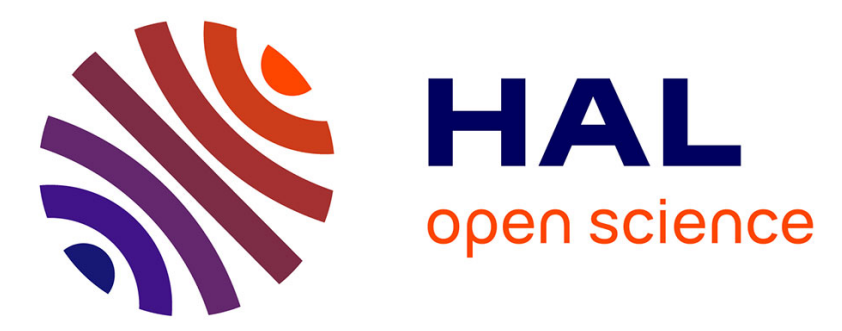

\title{
Selected Simple Indicators in the Field of Advanced Technologies as a Support of SMART Cities and Their Impact on Tourism
}

Libuše Svobodová, Miloslava Černá, Petr Hruša

\section{To cite this version:}

Libuše Svobodová, Miloslava Černá, Petr Hruša. Selected Simple Indicators in the Field of Advanced Technologies as a Support of SMART Cities and Their Impact on Tourism. 16th Conference on e-Business, e-Services and e-Society (I3E), Nov 2017, Delhi, India. pp.172-182, 10.1007/978-3-31968557-1_16. hal-01768518

\section{HAL Id: hal-01768518 \\ https://hal.inria.fr/hal-01768518}

Submitted on 17 Apr 2018

HAL is a multi-disciplinary open access archive for the deposit and dissemination of scientific research documents, whether they are published or not. The documents may come from teaching and research institutions in France or abroad, or from public or private research centers.
L'archive ouverte pluridisciplinaire HAL, est destinée au dépôt et à la diffusion de documents scientifiques de niveau recherche, publiés ou non, émanant des établissements d'enseignement et de recherche français ou étrangers, des laboratoires publics ou privés. 


\title{
Selected simple indicators in the field of advanced technologies as a support of SMART cities and their impact on tourism
}

\author{
Ing. Libuše Svobodová, Ph.D., Mgr. Miloslava Černá, Ph.D., Mgr. Petr Hruša, Ph.D. \\ University of Hradec Králové, Faculty of Informatics and Management, Rokitanského 62, 500 \\ 03, Hradec Králové, Czech Republic \\ libuse.svobodova@uhk.cz, miloslava.cerna@uhk.cz, \\ petr.hrusa@uhk.cz
}

\begin{abstract}
The paper discusses the issue of SMART cities in the context of tourism with a focus on utilization of technologies for travel purposes. Using the Pearson correlation coefficient, dependencies are calculated and analyzed between relative outbound tourism and selected simple indicators which are percentage of the internet users, availability of latest technologies, percentage of people speaking English at the communication level and mobile telephone subscriptions. All four correlated coefficients reached positive values. According to the theoretical bases we can state that there is dependence in all four cases. But mobile telephone subscriptions have a weak dependence. Percentage of the internet users reached the highest dependence. It is positive also for SMART cities. Official data from technical sources were used when working on the paper.
\end{abstract}

Keywords: tourism, Internet, Simple indicators, smart cities, advanced technologies

\section{Introduction}

Tourism is one of the indivisible areas of individual economies. While 20 years ago people used as main source of information materials of travel agencies, travel books, television documentaries, etc., nowadays travelers use advanced technology as the main sources of information. On the Internet and social networks, they search information on destinations, places to visit, accommodation, transport and many other. Technologies seem to be in tourism of vital importance as they are irreplaceable. Citizens get new mobile phones, tablets, computers, and so on. This way they also support the concept of SMART cities. Travelling and SMART cities as the key terms of this paper will be defined in the first chapter. Then environmental indicators will be described and characterized based on SMART concept.

In the main part of the paper, four simple indicators dealing with the use of advanced technologies will be discussed, e.g. individuals using internet, \% availability of latest technologies, English at the communication level and mobile phone subscriptions / 100 
pop. These indicators will be correlated with outbound tourism and through the Pearson correlation coefficient the impact of these indicators on tourism will be examined.

\subsection{Tourism and smart cities}

Tourism is a complex phenomenon comprising a wide range of disciplines. Due to that fact, defining tourism varies; definition of tourism is significantly influenced by its scope into other disciplines. Stating the appropriate definition is based on the intention of the technical report [1], research [2] or academic papers [3].

For the purposes of this paper the most frequently cited definition of 'Tourism' was selected. It is the definition from 1995 [4] created by the leading international organization in the field of tourism in the global scale [5] by The World Tourism Organization UNWTO which is still repeatedly used in UNWTO reports, e.g. Statistics of UNWTO [6].

The World Tourism Organisation UNWTO definition of Tourism is: "Tourism comprises the activities of persons travelling to and staying in places out-side their usual environment for not more than one consecutive year for leisure, business and other purposes not related to the exercise of an activity remunerated from within the place visited." [4]. This is a demand side definition, not a supply side definition [6].

As for the Czech Tourism [7] it is classified according to kinds and forms of tourism.

The most significant factor influencing the forms of tourism in the Czech Republic is motivation of visitors. The kinds of tourism are determined by the applied methodology. Zelenka and Pásková [8] state that individual forms and kinds of tourism can get combined as well as overlap each other.

Smart city is defined at Business Dictionary [9] as "a developed urban area that creates sustainable economic development and high quality of life by excelling in multiple key areas; economy, mobility, environment, people, living, and government. Excelling in these key areas can be done so through strong human capital, social capital, and/or ICT infrastructure."

Next definition is used from Innovation city. [10] Smart Cities is a vendor / city term commonly used to refer to the creation of knowledge infrastructure. Smart City, in everyday use, is inclusive of terms such as 'digital city' or 'connected cities'. Smart Cities as an applied technology term often refers to smart grids, smart meters, and other infrastructure for electricity, water supply, waste and what 2 thinknow refer to as, 'city basics'.

Times of India [11] used brief and the simplest definition. Smart city is "a city equipped with basic infrastructure to give a decent quality of life, a clean and sustainable environment through application of some smart solutions."

In the study of [29] smart city is defined as an ecosystem that is more than the sum of its parts, where sustainability is maintained through the interactions of urban functions.

Thompson [30] states that the answer to "What a smart city is?" is complex and it is not easy to define it. The answer depends on where the focus is and who is giving the answer. Although still a definitive definition is lacking, in many aspects this is by no means a terrible void. Smart City concept is wide and many players and notions are 
involved and therefore capturing all these elements in one definition might not be possible.

Albino, Berardi, and Dangelico's [31] paper is a great resource. They analysed several different definitions and clarified that perceiving and understanding of smart city phenomenon is changing and the smart city concept is no longer limited to the diffusion of ICT, but it looks at people and community needs. With this in mind the definition generated by the British Standards Institution [32] was selected; it focuses on integrating diverse systems namely, physical, digital and human systems is our preferred definition: Smart city is an effective integration of physical, digital and human systems in the built environment to deliver a sustainable, prosperous and inclusive future for its citizens. It is good to point out at this stage that as Gil-Garcia, Pardo, and Nam [33] explain being smart is not an end state, but rather can be an enabling condition that may lead to other desirable social, economic, or environmental outcomes. It is clear that, data and ICT play a big part in the smart future urbanism. But equally there are other major concepts contributing towards creation of smart cities. As Neirottio et al. [34] highlights, ICT is unable to transform cities without the human capital which brings the liveability of a city to attention. Angelidou [35] explains that, smart cities represent a conceptual urban development model based on the utilization of human, collective and technological capital for the enhancement of development and prosperity in urban agglomerations.

\subsection{The environmental indicator}

The paper discusses selected simple indicators. As an entry into this issue, the fundamental environmental indicator will be explained via definitions and characteristics gathered from local sources as well as international ones.

The first definition is taken from the local source. The environmental indicator is approached as a kind of information. The definition is descriptive, widely explanatory and easily understandable.

Hák [12] defined the environmental indicator as a type of information that provides a benchmark for assessing (mostly for quantitative assessing) of environmental trends, ecological policy goals, or health or ecosystem status. Indicators offer information which is simpler and easier to understand in comparison with information than we can find in statistics. Numeric indicators simplify information about complex phenomena, so they are clearly understandable and communicable. They are generated by the processing of primary data and thus constitute an empirical model of reality. Their calculation has to be justified and must be made in a clear way and preferably by an established method.

The following definition of the environmental indicator formulated by the Organization for Economic Cooperation and Development (OECD) might be considered as the fundamental definition accepted and frequently referred to by e.g. researchers or environmental policy makers in their countries. [13]

The OECD [14] definition of the environmental indicator is: "An environmental indicator is a parameter, or a value derived from parameters, that points to, provides information about and/or describes the state of the environment, and has a significance 
extending beyond that directly associated with any given parametric value. The term may encompass indicators of environmental pressures, conditions and responses."

Saunders et al. [15] state that environmental indicators can be described as physical, chemical, biological or socio-economic measures that best represent the key elements of a complex ecosystem or an environmental issue.

\subsection{Characteristics of indicators based on SMART concept}

Authors of the document Environmental indicators for reporting approached the issue basically to fit the needs of State of the Environment (SoE) reporting so that it could be possible to track environmental policy, its performance and results. They highlighted the importance of clearly stated objectives of what will be measured and that the indicators should be administratively practical and cost-effective to populate.

A SMART concept of indicators was designed. Characteristics of indicators in brief according to the "SMART" abbreviation concept follow:

- 'S ' stands for Simple (easily interpreted and monitored),

- 'M' means Measurable (statistically verifiable, reproducible and show trends),

- 'A' is Accessible (easily monitored, cost effective and consistent),

- R' stands for Relevant (directly address agreed objectives

- and ' $\mathrm{T}$ ' means Timely (for the purposes of State of the Environment reporting it should provide early warning of potential problems) [13].

The indicators can be categorized according to various criteria. The standard division of indicators is division into simple and complex indicators.

\section{Simple indicator}

Hák [12] defines a simple indicator as one-dimensional magnitude. It aims to give information about only one single phenomenon and its context. Most indicators are derived from primary data and are in the form of a simple indicator.

\section{Composite indicator}

Composite indicators group are more variables or different variables into one index. The goal of merging variables with the same properties into a single number is to describe their aggregate properties. Composite indicators can be created by different methodologies and include various components. Changes in index construction often cause confusion because indexes can give different information as compared to one another or even when refer-ring to long-term trends. [12] 


\section{$2 \quad$ Methodology and objectives}

The paper focuses on comparison of the degree of dependence between the inbound tourism and four selected simple indicators from the field of advanced technologies.

The aim is to introduce simple indicators that are most closely linked to tourism and advanced technologies that support the concept of SMART cities.

Hypothesis: Due to the importance of advanced technology in everyday life, tourism is related to the availability and use of advanced technologies in selected countries of the European Union.

\subsection{Statistical data processing}

Statistical correlation was used for statistical data processing.

Skalská [16] argues that correlation analysis deals with the measurement of relations between variables. Correlation analysis is used to quantify the association between two continuous variables i.e. between an independent and a dependent variable or between two independent variables. [17]. But Skalská [16] explains that the correlation is the degree of linear association between variables, when none of the variables needs to be labeled as dependent or independent.

Crossman [18] explains the Correlation as a term that refers to the strength of a relationship between two variables. A strong, or high, correlation means that two or more variables have a strong relationship with each other, while a weak or low correlation means that the variables are hardly related. Correlation analysis is the process of studying the strength of that relationship with available statistical data.

According to Litschmann [19] the tightness of linear dependence is assessed by a correlation coefficient. "The assessed relationship is the stronger and the regression function is the better, the more the monitored values of the variable are concentrated around the estimated regression function, and contrary the weaker, the more the values $y i$ are distant from balanced values."

\section{Pearson correlation coefficient}

The correlation coefficient is a measure of the linear dependence and is denoted. It can be explained as a share of covariance and the square root of the product of the scattering of variables, where the covariance expresses the relationship $\mathrm{X}$ and $\mathrm{Y}$, and the population scattering describes how much the data are scattered around the population average. [16], [20].

Formula for calculating the correlation coefficient:

$\rho(\mathrm{X}, \mathrm{Y})=(\mathrm{C}(\mathrm{X}, \mathrm{Y})) / \sqrt{ }(\mathrm{D}(\mathrm{X}) \mathrm{D}(\mathrm{Y}))$, where $\mathrm{D}(\mathrm{x}), \mathrm{D}(\mathrm{Y})$ denote population scattering. According to Skalská [13], the range of values is approximately

$0,1<|\rho| \leq 0,3$ indicates a weak dependence,

$0,3<|\rho| \leq 0,6$ mean medium dependence,

$0,6<|\rho| \leq 0,8 \quad$ we speak of strong dependence

$0,8<|\rho| \leq 0,9 \quad$ suggests a very strong dependence 
$|\rho| \geq 0,9$ almost linear dependence direct or indirect, according to the sign of the correlation coefficient. "

Skalská [16] warns that the general problem of observation and measurement can be the assumption of an association between two variables if the changes of both variables prove a certain connection. Skalská [16] points out that "the observed association (link) may be true, or it may be mediated by another variable (s) that is hidden". The author also states that a variable that is hidden or not included in the observation can affect the observed variables, which then appear to be related. For the interpretation of associations, it is necessary to know the context and the events that may influence the data compared.

\subsection{Statistics in tourism}

The content of the statistics in tourism is described in this chapter from global and local perspectives, from the international UNWTO perspective and from the national perspective represented by Czech Statistical Office of the Czech Republic.

The statistics in tourism deals with the collection of statistical data from various areas of tourism, their processing and comparison, both at the regional and as well as at the international level. Statistical data refer to the profile of tourism participants, occupancy of accommodation facilities or means of transport, outbound tourism or customer satisfaction with the services provided. Statistics deals not only with collection of data but it deals also with the creation of statistical methodologies and their processing. Gained data are available and used by both professional and general public in private and public spheres.

The UNWTO as the United Nations agency responsible for the promotion of responsible, sustainable and universally accessible tourism defines the content of Statists in tourism as follows:

"The UNWTO systematically gathers tourism statistics from countries and territories around the world into a vast database that constitutes the most comprehensive statistical information available on the tourism sector. The database, updated regularly, is composed by the following sets of data [21]:

- Compendium of Tourism Statistics - The Compendium provides statistical data and indicators on inbound, outbound and domestic tourism, as well as on the number and types of tourism industries, the number of employees by tourism industries, and macroeconomic indicators related to international tourism.

- Yearbook of Tourism Statistics - The Yearbook focuses on data related to inbound tourism (total arrivals and overnight stays), broken down by country of origin.

- Outbound tourism data (estimates) tourism of resident visitors outside the economic territory of the country of reference".

The Czech Republic is a member of the European Union. In the Czech Republic, Tourism statistics is coordinated by the Czech Statistical Office. Websites of this state important body are systematically updated and coordinated with Statistical offices of other 
European countries as well as the UNWTO. Websites bring Data encompassing Latest figures in News Releases, Time series, Tourism Satellite Account, Selected tables from the Public Database, another large section represents Methodology covering Tourism - Methodology and Metadata and quality reports, the last section brings a wide range of analyses. [22]

Tourism has an enormous economic potential. In the EU the role of tourism is discussed in its social and environmental implications. Eurostat statistics websites provide recent statistics from Tourism in individual states of the European Union as well as the EU as a whole. [23]

\section{Correlation of simple indicators}

A total of 60 simple indicators from the fields of economics, sociology and ecology were analyzed in the research. Selected results from the research are presented in this paper. The strength of dependence on the relative outbound tourism for 2014 was determined. The analysed EU states do not include Croatia, Ireland, Malta, Bulgaria, Greece, Slovenia, Luxembourg and Cyprus. Data for the results of the indicators come from the Global Competitiveness Index [24], the OECD Better Life Index 2014 [25], Wikipedia [26] and Numbeo [27] websites, all data relate to 2014. Data for relating to the share of English-speaking inhabitants are from to 2012 for France, Italy, Austria, Denmark, Finland, the Czech Republic, Hungary, Slovakia, Lithuania, Latvia, Estonia, Romania, the Netherlands, Spain and Sweden, as for the United Kingdom of Great Britain and Northern Ireland the data relate to 2011 and older data coming from 2006 relate to Germany and Belgium. As for Poland the data are recorded but without the year of their collection.

All data of the outbound tourism were drawn from Eurostat and consequently processed by authors. The data relate to 2014 .

The following part discusses four simple indicators. Three of them demonstrated the highest rates of dependency and ranked among the top ten indicators. The crucial reason for selection of these specific indicators was their relation to the advanced technologies which represent fundamental area for the development of the Information and communication (ICT) literacy and for the creation and efficient operation of SMART cities.

The results of the correlations of the analyzed simple indicators are shown in the table below. There are analysed relative outbound tourism with percentage of the internet users, availability of latest technologies, percentage of people speaking English at the communication level and mobile telephone subscriptions. All four correlated coefficients reached positive values as is illustrated in the Table 1. According to the theoretical bases we can state that it is in the first three cases the strong or medium dependence. In the last one case is the dependence weak. 


\begin{tabular}{lcccc}
\hline Country & $\begin{array}{l}\text { Individuals us- } \\
\text { ing Internet, } \%\end{array}$ & $\begin{array}{l}\text { Availability of } \\
\text { latest technolo- } \\
\text { gies }\end{array}$ & $\begin{array}{l}\text { English at the } \\
\text { communication } \\
\text { level }\end{array}$ & $\begin{array}{l}\text { Mobile telephone } \\
\text { subscriptions/100 } \\
\text { pop. }\end{array}$ \\
\hline Belgium & 85 & 6,2 & 38 & 114,3 \\
Czech Republic & 79,7 & 5,6 & 27 & 130 \\
Denmark & 96 & 6 & 86 & 126 \\
Estonia & 84,2 & 5,8 & 50 & 160,7 \\
Finland & 92,4 & 6,6 & 70 & 139,7 \\
France & 83,8 & 6 & 39 & 100,4 \\
Germany & 86,2 & 6,2 & 56 & 120,4 \\
Great Britain & 91,6 & 6,5 & 98 & 123,6 \\
Hungary & 76,1 & 5,1 & 20 & 118,1 \\
Italy & 62 & 5,1 & 34 & 154,2 \\
Latvia & 75,8 & 5,8 & 46 & 124,2 \\
Lithuania & 72,1 & 5,8 & 38 & 147 \\
Netherlands & 93,2 & 6,3 & 90 & 116,4 \\
Poland & 66,6 & 4,6 & 33 & 156,4 \\
Portugal & 64,6 & 6,1 & 27 & 110 \\
Romania & 54,1 & 4,6 & 31 & 105,9 \\
Slovakia & 80 & 5,5 & 26 & 116,9 \\
Spain & 76,2 & 5,5 & 22 & 107,8 \\
Sweden & 92,5 & 6,5 & 86 & 127,8 \\
\hline Correlation & 0,713338809 & 0,576664394 & 0,55514043 & 0,057982463 \\
\hline
\end{tabular}

Table 1. Correlation of the relative outbound tourism and four selected simple indicators related to the use of advanced technologies with the highest correlation rate. Source: wwn processing based on data from Schwab [24], Organization for Economic Cooperation and Development [25], Wikipedia [26] and Numbeo [27]

The highest rate of dependence on the relative outbound tourism out of the 60 simple indicators analysed was achieved by a simple indicator of the percentage of users using the Internet. The correlation coefficient was 0.71 . This is, therefore, a strong dependence between investigated items. It can be interpreted that the outbound tourism per person increases with a higher number of Internet users. It is understandable, because these days the Internet is the main source of information in general as well as for the purposes of tourism. In addition, gaining information on foreign destinations, weather, exchange rates and prices is very cheap, fast, convenient and accessible at anytime from anywhere thanks to the internet.

The indicator of the latest technology availability shows moderate dependence on the outbound tourism. It can be deduced that the outbound tourism is more or less growing with better access to the latest technology. Modern technology moves human possibilities, whether it is information, security or accessibility. The latest technologies 
push the boundaries of the tourism and have a significant impact on its quality of service. This naturally leads to an increase in the number of tourists.

The ten strongest correlation relationships are concluded by the indicator of the percentage of people speaking English at least at the communicative level. The correlation coefficient is 0.55 . From these results it can be concluded that the number of foreign visits will increase more or less with the increasing number of people who can speak English. The dependence is medium. The authors claim that the ability to communicate in English can break the anxiety from cultural barriers, the unfamiliar environment, and the unexpected situations that can happen during a trip abroad. The authors believe that the ability to communicate in a foreign language abroad significantly affects people's decision whether to travel beyond the borders of the state or not.

Even though there are more than one Mobile phone subscriptions in each monitored country and mobile phones are actively used, they have a very low correlation with tourism. To give an example, in Austria, Estonia, Italy, Poland there is more than 1.5 accounts per capita. On the contrary, the lowest share was recorded in France, Romania and Spain.

\section{Conclusion}

The paper discusses the basic concepts and principles of tourism, economy and the use of technologies and language competences in travel as a support for utilization of SMART technology and impact on destinations. Knowledge of basic concepts of mentioned areas and understanding their interconnectedness is necessary for the subsequent exploration of their relationships. In order to compare the dependencies between the items, the relevant issues from statistics and the Pearson correlation coefficient are explained.

Theoretical knowledge was applied to the correlation of the relative outbound tourism and selected simple indicators. The correlation results were processed into tables, compared, analyzed and interpreted. All correlated coefficients reached positive values as is illustrated in the Table 1. According to the theoretical bases we can state that there is the dependence in all four cases.

The first place in the top ten simple indicators with the highest coefficient belongs to users of the Internet. The eight position out of ten belongs to the availability of advanced technologies and the tenth place the percentage of people speaking English at least at the communicative level. A note should be made on incorporation of the mobile telephones indicator into the paper; mobile phones are not linked to tourism but majority of people use them as a standard device when they are travelling.

Given the above results, the assumed hypothesis can be accepted. Due to the importance of advanced technology in everyday life, tourism is related to the availability and use of advanced technologies in selected countries of the European Union.

The percentage of users using the Internet gained a correlation of 0.71 , the availability of the latest technologies 0.58 , the percentage of people speaking at a communicative level of 0.56 . The number of mobile phones per 100 inhabitants showed only 0.16 which is a weak dependence. 
The crucial reason for selection of specific indicators was their relation to the advanced technologies which represent fundamental area for the development of the Information and communication (ICT) literacy and for the creation and efficient operation of SMART cities.

As a theoretical contribution of the paper might be perceived following, users of the Internet, availability of the latest advanced technologies and the percentage of people speaking English at least at the communicative level have a significant impact on tourism. Mobile phones have lesser influence than other categories. The results and findings are beneficial not only for the academic area but also for the business entities that sell or provide the given products and as well as for the general public. By linking two areas that are tourism and technology and communication, the issue can be of interest to both urban experts and people in tourism. Not only tourist destinations, but also travel agencies, information centers, towns, castles, castles or chateaus should nowadays use advanced technologies to promote their attractions, thus boost tourism that has a positive impact on the economic situation and development. In conclusion, this is an interesting issue with great potential for the future.

\section{Acknowledgement}

This paper is supported by internal grant No. 1907/2017 "Transformation of knowledge from the field of kinanthropology into geography and tourism" at Faculty of Informatics and Management, University of Hradec Kralove, Czech Republic.

\section{$5 \quad$ References}

1. UNWTO - Tourism Highlights 2016. http://fac.ksu.edu.sa/sites/default/files/tourism_highlights_2016-_unwto.pdf

2. Jennings G (2001) Tourism research. - CAB Direct. https://www.cabdirect.org/cabdirect/abstract/20023031452

3. Progress in Tourism and Hospitality Research. http://onlinelibrary.wiley.com/journal/10.1002/(ISSN)1099-1603

4. UNWTO (1995:1-2): Concepts, Definitions, and Classifications for Tourism Statistics. Technical Manual: Technical Manual. Madrid: World Tourism Organization, 1995.

5. UNWTO - Who we are. http://www2.unwto.org/content/who-we-are-0

6. World Tourism Organisation - Statistics and Tourism Satellite Account. http://statistics.unwto.org/sites/all/files/pdf/unwto_tsa_1.pdf 2011.

7. CZECHTOURISM (2016) Charakteristika a význam cestovního ruchu v Česku. In: CzechTourism: 20 let s vámi. http://old.czechtourism.cz/didakticke-podklady/1-charakteristika-avyznam-cestovniho-ruchu-v-cesku/

8. Zelenka J, Pásková M (2012) Výkladový slovník cestovního ruchu. Kompletně přeprac. a dopl. 2. vyd. Praha: Linde Praha.

9. Smart city. Definition of SMART city. http://www.businessdictionary.com/definition/smart-city.html

10. Innovation cities. Definition of SMART city. http://www.innovation-cities.com/a-definition-of-a-smart-cities-compared-with-an-innovation-city/1322

11. Times of India. Definition of SMART city. http://timesofindia.indiatimes.com/What-is-asmart-city-and-how-it-will-work/listshow/47128930.cms 
12. Hák, T. (2010) Indikátory blahobytu: všechno, co jste kdy chtěli vědět o štěstí (ale báli jste se zeptat). http://www.zelenykruh.cz/o-nas/publikace/edice-apel

13. Department of the Environment and Heritage 2006, 'Environmental indicators for reporting'. https://www.environment.gov.au/node/22551

14. Environmental Indicator OECD Glossary of statistical terms. https://stats.oecd.org/glossary/detail.asp?ID=830

15. Saunders DC, Margules C and Hill B (1998) Environmental indicators for national state of the environment reporting-Biodiversity, Australia: State of the Environment (Environmental Indicator Reports), Department of the Environment, Canberra.

16. Skalská H (2013) Aplikovaná statistika. Hradec Králové: Gaudeamus

17. Multivariable Methods. http://sphweb.bumc.bu.edu/otlt/mph-modules/bs/bs704_multivariable/bs704_multivariable5.html

18. Crossman A (2016) Understanding Correlation Analysis. https://www.thoughtco.com/whatis-correlation-analysis-3026696

19. Litschmannová M. (2012) Úvod do statistiky: interaktivní učební text. http://mi21.vsb.cz/sites/mi21.vsb.cz/files/unit/interaktivni_uvod_do_statistiky.pdf

20. Hudecová Š (2012) Matematická statistika. http://www.karlin.mff.cuni.cz/ hudecova/education/archive11/download/chem_predn/predn_slides_05.pdf

21. Statistics and Tourism Satellite Account (2013). http://statistics.unwto.org/content/data-1

22. Tourism. Czech Statistical Office. (2016) https://www.czso.cz/csu/czso/tourism_ekon

23. Tourism statistics (2016) http://ec.europa.eu/eurostat/statistics-explained/index.php/Tourism_statistics

24. Schwab, K. (ed.). The Global Competitiveness Report 2015-2016: Insight Report (2015). http://www3.weforum.org/docs/gcr/2015-2016/Global_Competitiveness_Report_20152016.pdf

25. Organisation for Economic Co-operation and Development. (2016): Average annual hours actually worked per worker. https://stats.oecd.org/Index.aspx?DataSetCode=ANHRS

26. Wikipedia (2016) List of countries by English-speaking population. https://en.wikipedia.org/wiki/List_of_countries_by_English-speaking_population

27. Numbeo (2016): Quality of Life Index for Country 2016 Mid Year. http://www.numbeo.com/quality-of-life/rankings_by_country.jsp?title=2016-mid

28. Gottschalk M, Uslar M (2016) Using a Use Case Methodology and an Architecture Model for Describing Smart City Functionalities. International journal of electronic government research. 12(2), pp 1-17.

29. Rochet C, Correa JDP (2016) Urban Lifecycle Management: A Research Program for Smart Government of Smart Cities. Revista de Gestão e Secretariado, Vol. 7(2), pp. 1-20

30. Thompson EM (2016). Smart City: Adding to the Complexity of Cities A Critical Reflection. In: 34th eCAADe Conference: complexity \& simplicity (eCAADe 2016), Finland: University Oulu, pp 651-660.

31. Albino V, Berardi U, Dangelico RM (2015) Smart Cities: Definitions, Dimensions, Performance, and Initiatives. Journal of Urban Technology. Vol. 22(1), pp. 3-21

32. BSI standards publication. http://shop.bsigroup.com/upload/PASs/Free-Download/PAS180.pdf

33. Garcia G, Pardo TA, Nam T. (2016) Smarter as the New Urban Agenda. A Comprehensive View of the 21st Century City. Springer International Publishing. Vol. 11

34. Neirotti P, De Marco A, Cagliano AC, Mangano G and Scorrano F (2014) Current trends in Smart City initiatives: Some stylised facts. Cities, 38, pp. 25-36

35. Angelidou M (2014) Smart city policies: A spatial approach. Cities. 41, pp. 3-11 